\title{
Pengaruh Transparansi Dan Akuntabilitas Laporan Keuangan Terhadap Kepercayaan Donatur Di Yayasan Sosial Keagamaan
}

\author{
${ }^{1}$ Nikmahtul Maulidiyah, ${ }^{2}$ Darno \\ ${ }^{1,2}$ Fakultas Ekonomi dan Bisnis , Universitas Maarif Hasyim Latif Sidoarjo \\ E-mail: ${ }^{1}$ nikmahtul-maulidiyah@ @student.umaha.ac.id, ${ }^{2}$ darno@dosen.umaha.ac.id
}

\section{ARTICLE INFO}

\section{Keywords}

Transparency, accountability, trust

\begin{abstract}
The Yadufa Cup Religious Social Foundation is a non-profit entity that is aware of its rights and obligations as well as its roles and responsibilities to Islam, the homeland and the nation. This foundation also has ZISWAH services (Zakat, Infaq, Shodaqoh, Endowments and Grants) which will later be distributed to Yadufa and empowered for social and community. This study aims to determine whether there is an influence of financial report transparency on donor trust in the Yadufa Cup of Religious Social Foundation. The research method uses quantitative research using the RLB test. This research produces 3 things: the first, that the transparency of financial statements does not significantly influence the trust of donors. Second, it shows that the accountability of financial statements has a significant effect on the trust of donors. Third, it shows that the transparency and accountability of financial statements simultaneously influences donor trust. Based on the RLB analysis, the transparency and accountability of financial statements can be a predictor of the trust of donors at the Yadufa Cup of Religious Social Foundation. The SEE value turns out to be smaller than the standard deviation value, so this regression model can be used as a prediction of the level of trust of donors in the future.
\end{abstract}

\section{PENDAHULUAN}

Organisasi nirlaba merupakan entitas non provit yang bersasaran pokok dalam mendukung suatu isu maupun perihal, untuk menarik perhatian publik dalam mencapai tujuan tanpa memperoleh keuntungan. Menurut PSAK No. 45 karateristik entitas nirlaba berbeda dengan entitas lainnya, cara entitas nirlaba dalam mendapatkan sumber daya yang diperlukan dalam melasanakan aktivitas operasionalnya merupakan salah satu perbedaan dari entitas nirlaba dengan entitas yang berorentasi dengan profit.

Entitas nirlaba, salah satunya badan yang berbentuk yayasan juga dituntut untuk menyajikan laporan keuangan. Laporan keuangan sangat penting bagi suatu entitas nirlaba. Untuk itu Ikatan Akuntan Indonesia mengeluarkan definisi Standar Akuntansi Keuangan No. 45 tentang laporan keuangan entitas nirlaba. Pernyataan Standar Akuntansi Keuangan No. 45 menjelaskan tujuan laporan keuangan entitas nirlaba dimana kepentingan para donatur dan penyedia sumber daya memperoleh informasi yang relevan. Untuk menciptakan Good Governance pada suatu yayasan harus ditandai dengan adanya transparansi dan akuntabilitas dalam pengelolaannya.

Bentuk pertanggungjawaban entitas nirlaba dalam hal pengelolaan dana, para donatur biasanya meminta adanya suatu pelaporan keuangan yang transparan, agar dapat memberikan informasi yang relevan terhadap para dermawan yang telah menyerahkan sumber dayanya bagi yayasan tersebut. Pelaporan keuangan yang tidak akuntanbel serta transparan, akan mempengaruhi kepercayaan donatur terhadap pengelola yayasan, karena para donatur beranggapan bahwa pengendalian sumber daya yang telah diberikan tidak dikelola dan disalurkan dengan baik. Untuk itu transparasi dan akuntabilitas laporan keuangan sangat diperlukan. Berlandaskan latar belakang diatas, judul yang ingin diambil oleh penulis adalah "Pengaruh Transparasi dan Akuntabilitas Laporan Keuangan Terhadap Kepercayaan Donatur Di Yayasan 
Sosial Keagamaan Cangkir Yadufa". Berdasarkan latar belakang tersebut maka identifikasi permasalahan penelitian ini yaitu :

\section{Rumusan Masalah :}

1. Apakah terdapat pengaruh transparasi laporan keuangan terhadap kepercayaan donatur di Yayasan Sosial Keagamaan Cangkir Yadufa?

2. Apakah terdapat pengaruh akuntabilitas laporan keuangan terhadap kepercayaan donatur di Yayasan Sosial Keagamaan Cangkir Yadufa?

3. Apakah terdapat pengaruh antara transparasi dan akuntabilitas secara bersama-sama terhadap kepercayaan donatur di Yayasan Sosial Keagamaan Cangkir Yadufa?

\section{Tujuan Penelitian :}

1. Untuk mengetahui ada tidaknya pengaruh transparansi laporan keuangan terhadap kepercayaan donatur di Yayasan Sosial Keagamaan Cangkir Yadufa?

2. Untuk mengetahui ada tidaknya pengaruh akuntabilitas laporan keuangan terhadap kepercayaan donatur di Yayasan Sosial Keagamaan Cangkir Yadufa?

3. Untuk mengetahui ada tidaknya pengaruh transparansi dan akuntabilitas secara bersama-sama terhadap kepercayaan donatur di Yayasan Sosial Keagamaan Cangkir Yadufa?

\section{TINJAUAN PUSTAKA}

\section{Pengertian Transparansi}

Transparansi yakni keterbukaan serta kejujuran kepada masyarakat atas apa yang telah menjadi haknya untuk mengetahui secara umum dan menyeluruh atas sesuatu yang dipertanggungjawabkan untuk mengelola sumber daya yang diamanahkan.

Menurut mardiasmo dalam (Maryati, 2012). Informasi yang berhubungan dengan aktivitas sumber daya publik terhadap masyarakat maupun pihak yang membutuhkan yang diberikan oleh pemerintah secara terbuka.

\section{Pengertian Akuntabilitas}

Akuntabilitas yakni bentuk kesanggupann seseorang maupun kelompok dalam menyampaikan jawaban kepada kekuasaan yang tertinggi atas usaha seseorang maupun kelompok yang terdapat pada rakyat umum dalam suatu organisasi. Syahrudin Rasul, (2002:8).

\section{Pengertian Kepercayaan}

Kepercayaan adalah suatu keinginan yang dimiliki oleh pribadi untuk bergantung kepada pribadi yang lain, dimana ada rasa keyakinan yang lebih terhadap pribadi tersebut. Dalam konteks sosial tingkat kepercayaan seseorang terhadap orang lain yang ia percayai akan sangat berdampak pada saaat proses pengambilan keputusan, dimana keputusan yang akan ia ambil berlandaskan opsi dari orang lain yang dipercayainya daripada orang yang kurang dipercayainya. (Moorman, 1993).

Kepercayaan donatur terhadap yayasan diartikan sebagai tingkat keyakinan bahwa donatur telah menyumbangkan sumber dayanya dengan tepat, yang akan menguntungkan bagi donatur itu sendiri dan bagi yayasan dalam mencapai tujuannya.

\section{METODOLOGI PENELITIAN}

\section{Model Penelitian}

Model penelitian ini memakai metode kuantitatif, penelitian kuantitatif yakni penelitian yang berhubungan dengan angka-angka dan dapat di ukur.

\section{Populasi dan sampel}

Populasi terhadap penelitian ini yakni kumpulan suatu objek yang memiliki kualitas dan karateristik tertentu yang nantinya akan dipilih untuk dijadikan sasaran penelitian. Sampel yakni bagaian dari jumlah dan karateristik yang dipunyai oleh populasi tersebut. Populasi penelitian ini yaitu donatur Yayasan Sosial Keagamaan Cangkir Yadufa, sedangkan sampel penelitian ini adalah 35 donatur yang bertempat tinggal di Desa Bringin Wetan wilayah Yayasan Sosial Keagamaan Cangkir Yadufa berdiri.

\section{Teknik Pengumpulan Data}


Teknik pengumpulan data penelitian ini menggunakan teknik kuesioner dengan menyebarkan atau memberikan daftar pernyataan kepada para responden dan menggunakan teknik dokumentasi.

\section{Teknik Analisis Data}

Teknik analisis data penelitian ini yaitu menggunakan analisis RLB dengan bantuan aplikasi SPSS 16. Dengan pengujian uji validitas, uji reliabilitas, uji normalitas data, uji multikolonieritas, uji hipotesis, dan uji koefisien determinasi.

\section{HASIL PENELITIAN DAN PEMBAHASAN}

\section{Gambaran Umum Penelitian}

Penelitian ini dilakukan di Yayasan Sosial Keagamaan Cangkir Yadufa yang berada di Desa Bringin Wetan Rt: 07 Rw: 06 Taman-Sisoarjo. Yayasan Sosial Keagamaan Cangkir Yadufa merupakan yayasan nirlaba yang sadar akan hak dan kewajiban serta peranan dan tanggung jawabnya kepada Islam, nusa serta bangasa. Yayasan ini juga mempunyai layanan ZISWAH (Zakat, Infaq, Shodaqoh, Wakaf, dan Hibah) umat Islam untuk disalurkan kepada para anak yatim dan kaum duafa serta diberdayakan untuk sosial agama dan kemasyarakatan.

\section{Deskripsi Responden}

Kuesioner dibagikan kepada para donatur sebanyak 35 responden, setiap responden memiliki karateristik yang berbeda-beda, karateristik responden penelitian ini terbagi jadi dua, yakni berdasarkan kesetaraan gender dan berdasarkan tingkat pendidikan.

\section{Hasil Uji Validitas Data}

Hasil uji validitas data memperelihatkan bahwa nilai $\mathrm{r}$ hitung dari item pernyataan untuk semua variabel lebih besar dari $r$ tabel. Hal tersebut memiliki arti bahwa item pernyataan untuk variabel transparansi, akuntabilitas dan kepercayaan .

\section{Hasil Uji Reliabilitas}

Hasil uji reliabilitas menerangkan bahwa besarnya alpha cronbach dari seluruh variabel lebih besar dari 0.6. Artinya, bahwa semua variabel reliable. Hasil dari uji reliable ditunjukkan pada tabel di bawah ini.

Tabel 4.1

Uji Reliabilitas Transparansi

\begin{tabular}{|c|c|}
\hline Cronbach's Alpha & N of Items \\
\hline 0.560 & 8 \\
& \\
\hline
\end{tabular}

Sumber: Data diolah spss 16

Tabel 4.2

Uji Reliabilitas Akuntabilitas

\begin{tabular}{|c|c|}
\hline Cronbach's Alpha & $\begin{array}{c}\text { N of } \\
\text { Items }\end{array}$ \\
\hline 0.348 & 8 \\
\hline
\end{tabular}

Sumber: Data diolah spss 16

Tabel 4.3

Uji Reliabilitas Kepercayaan

\begin{tabular}{|c|c|}
\hline Cronbach's Alpha & N of Items \\
\hline 0.508 & 8 \\
\hline
\end{tabular}

Sumber: Data diolah spss 16 


\section{Hasil Uji Normalitas}

Hasil uji normalitas membuktikan variabel transparansi, akuntabilitas dan kepercayaan donatur, masing-masing memiliki nilai asymp sig lebih besar dari 0.05 . Hal ini diartikan bahwa masing-masing variabel berdistribusi normal. Berikut merupakan hasil uji normalitas data dan hasil analisis yang dilakukan:

Tabel 4.4

Uji Normalitas

\begin{tabular}{|c|c|c|c|}
\hline Variable & Signifikansi & $\mathrm{a}=5 \%$ & Keterangan \\
\hline Transparansi & 0.980 & 0.05 & Normal \\
\hline Akuntabilitas & 1.228 & 0.05 & Normal \\
\hline $\begin{array}{c}\text { Kepercayaan } \\
\text { Donatur }\end{array}$ & 1.001 & 0.05 & Normal \\
\hline
\end{tabular}

Sumber: Data diolah spss 16

\section{Hasil Uji Multikolonieritas}

Hasil dari uji multikolonieritas menunjukkan bahwa nilai tolerance pada variabel transparansi dan akuntabilitas diatas 0,1 sehingga bisa disimpulkan bahwa persamaan regresi tersebut memenuhi asumsi bebas multikolonieritas. Sedangkan nilai VIF pada variabel transparansi dan akuntabilitas menunjukkan nilai diatas 0,1 sehingga bisa disimpulkan bahwa antar variabel tidak terjadi masalah multikolonieritas. Hasil uji multikolonieritas dapat dilihat pada tabel dibawah ini:

Tabel 4.5

Uji Multikolonieritas

Coefficients $^{\mathrm{a}}$

\begin{tabular}{|c|l|c|c|}
\hline \multicolumn{2}{|c|}{ Model } & \multicolumn{2}{c|}{ Collinearity Statistics } \\
\cline { 3 - 4 } \multicolumn{2}{|c|}{} & Tolerance & VIF \\
\hline \multirow{2}{*}{1} & Transparansi & 623 & 1.606 \\
\cline { 2 - 4 } & Akuntabilitas & 623 & 1.606 \\
\hline
\end{tabular}

a. Dependent Variable : Kepercayaan Donatur

Sumber: Data diolah spss 16

\section{Hasil Uji Regresi Linear Berganda}

Berdasarkan hasil perhitungan statistik pada uji RLB dapat dilihat pada tabel dibawah ini: 
Tabel 4.6

Descriptive Statistic

Descriptive Statistic

\begin{tabular}{|c|c|c|c|}
\hline & Mean & $\begin{array}{c}\text { Std. } \\
\text { Deviation }\end{array}$ & N \\
\hline Kepercayaan & 30.69 & 3.297 & 35 \\
\hline Transparansi & 32.80 & 3.085 & 35 \\
\hline Akuntabilitas & 32.60 & 3.727 & 35 \\
\hline \multicolumn{2}{c}{ Sumber: Data diolah spss 16} \\
\end{tabular}

Tabel 4.6 memberikan penjelasan mengenai besarnya mean dan besarnya nilai standart deviasi masing-masing variabel.

Tabel 4.7

\section{Correlations}

Correlations

\begin{tabular}{|c|c|c|c|c|}
\hline & & $\begin{array}{c}\text { Kepercayaa } \\
n\end{array}$ & $\begin{array}{c}\text { Transparan } \\
\text { si }\end{array}$ & Akuntabilitas \\
\hline \multirow{3}{*}{$\begin{array}{l}\text { Pearson } \\
\text { Correlatio } \\
n\end{array}$} & $\begin{array}{l}\text { Kepercayaa } \\
n\end{array}$ & 1.000 & .413 & .722 \\
\hline & $\begin{array}{l}\text { Transparan } \\
\text { si }\end{array}$ & .413 & 1.000 & .614 \\
\hline & $\begin{array}{l}\text { Akuntabilita } \\
\text { s }\end{array}$ & .722 & .614 & 1.000 \\
\hline \multirow{3}{*}{$\begin{array}{l}\text { Sig. (1- } \\
\text { Tailed) }\end{array}$} & $\begin{array}{l}\text { Kepercayaa } \\
\text { n }\end{array}$ & & .007 & .000 \\
\hline & $\begin{array}{l}\text { Transparan } \\
\text { si }\end{array}$ & .007 & . & .000 \\
\hline & $\begin{array}{l}\text { Akuntabilita } \\
\text { s }\end{array}$ & 0 & 0 & . \\
\hline \multirow{3}{*}{$\mathrm{N}$} & $\begin{array}{l}\text { Kepercayaa } \\
\text { n }\end{array}$ & 35 & 35 & 35 \\
\hline & $\begin{array}{l}\text { Transparan } \\
\text { si }\end{array}$ & 35 & 35 & 35 \\
\hline & $\begin{array}{l}\text { Akuntabilita } \\
\text { s }\end{array}$ & 35 & 35 & 35 \\
\hline
\end{tabular}

Sumber: Data diolah spss 16

Tabel 4.7 memberikan informasi mengenai hubungan antar tiap-tiap variabel dengan nilai $\mathrm{p}$ value masing-masing variabel $<0.05$. Dengan begitu, dapat dikatakan terdapat hubungan yang sedang dan signifikan antara transparansi terhadap kepercayaan donatur, serta diperoleh hubungan yang tinggi/kuat antara akuntabilitas terhadap kepercayaan donatur. 
Tabel 4.8

Coefficients $^{\mathrm{a}}$

Coefficients $^{\mathrm{a}}$

\begin{tabular}{|c|c|c|c|c|c|c|c|}
\hline \multirow[t]{2}{*}{ Model } & \multicolumn{2}{|c|}{$\begin{array}{l}\text { Unstandardized } \\
\text { Coefficients }\end{array}$} & \multirow[t]{2}{*}{$\begin{array}{c}\text { Standar } \\
\text { dized } \\
\text { Coeffici } \\
\text { ents }\end{array}$} & \multirow{2}{*}{$\mathrm{T}$} & \multirow[t]{2}{*}{ Sig. } & \multicolumn{2}{|c|}{$\begin{array}{l}\text { Collinearity } \\
\text { Statistics }\end{array}$} \\
\hline & $B$ & $\begin{array}{l}\text { Std. } \\
\text { Error }\end{array}$ & & & & $\begin{array}{c}\text { Tolera } \\
\text { nce }\end{array}$ & VIF \\
\hline (Constant) & 10.722 & 4.446 & & 2.412 & 0.022 & & \\
\hline $\begin{array}{l}\text { Transparans } \\
\text { i }\end{array}$ & -0.052 & 0.165 & -0.049 & -317 & 0.754 & 0.623 & 1.606 \\
\hline $\begin{array}{l}\text { Akuntabilita } \\
\text { s }\end{array}$ & 0.665 & 0.137 & 0.752 & 4.857 & 0.000 & 0.623 & 1.606 \\
\hline
\end{tabular}

c. Dependen Variable: Kepercayaan

\section{Sumber: Data diolah Spss 16}

Dari tabel diatas diperoleh persamaan RLB sebagai berikut:

$\mathrm{Y}=\mathrm{a}+\mathrm{b} 1 \mathrm{X} 1+\mathrm{b} 2 \mathrm{X} 2$

$Y=10.722+-0.052 \mathrm{X} 1+0.665+0.665 \mathrm{X} 2$

$\mathrm{Y}=10.722+0+0$

$\mathrm{Y}=10.722$

Yang berarti apabila transparansi $=0(\mathrm{X} 1=-0)$, dan akuntabilitas $=0(\mathrm{X} 2=0)$, maka kepercayaan donatur sebesar 10.722 .

Hal tersebut menjelaskan bahwa transparansi dan akuntabilitas terhadap kepercayaan donatur akan mengalami peningkatan sebesar 10.722 .

Tabel 4.9

Model Summary

\begin{tabular}{|c|c|c|c|c|}
\hline \multicolumn{5}{|c|}{ Model Summary } \\
\hline Mode & $\mathrm{R}$ & R Square & $\begin{array}{l}\text { Adjusted } \\
\text { R Square } \\
\text { Std. } \\
\text { Error of } \\
\text { the } \\
\text { Estimate }\end{array}$ & $\begin{array}{l}\text { Std. Error of } \\
\text { the Estimate }\end{array}$ \\
\hline 1 & $.723^{\mathrm{a}}$ & .523 & .493 & 2.348 \\
\hline
\end{tabular}

Sumber: Data diolah spss 16

Tabel 4.9 memaparkan informasi tentang nilai koefisien determinasi. Nilai koefisien determinasi diperoleh besar nilai koefisien regresi transparansi, akuntabilitas, serta kepercayaan donatur sebesar 0.723 (tinggi/kuat). $\mathrm{R}$ square $0.523(0.523 \times 100 \%)$, hal ini dapat diketahui bahwa variabel transparansi, 
akuntabilitas memberikan pengaruh terhadap variabel kepercayaan donatur sebesar 52,3\% dan sisanya 47,7\% dipengaruhi oleh variabel-variabel lain. dan diperoleh nilai SEE 2.348, serta nilai simpangan baku, yakni 3.297. Hal ini menerangkan bahwa nilai SEE ternyata lebih kecil daripada nilai simpangan baku, hal ini berarti model regresi ini nantinya dapat dipergunakan untuk memprediksi mengenai tingkat kepercayaan donatur di kemudian hari.

\section{Hasil Uji Statistik (t)}

Mengacu pada tabel 4.8 diperoleh hasil sebagai berikut:

\section{A. Hasi uji hipotesis 1}

Pengaruh transparansi laporan keuangan terhadap kepercayaan donatur.

Hasil uji hipotesis 1 bisa dilihat pada tabel 4.8, variabel transparansi diperoleh nilai sig 0.754 . Hal tersebut menerangkan bahwa $\mathrm{H}_{\mathrm{o}}$ diterima, yang bermakna variabel transparansi tidak berpengaruh terhadap kepercayaan donatur. Karena nilai sig lebih besar dari 0.05 .

\section{B. Hasil uji hipotesis 2}

Pengaruh akuntabilitas laporan keuangan terhadap kepercayaan donatur.

Hasil uji hipotesis 2 dapat dilihat pada tabel 4.8, variabel akuntabilitas diperoleh nilai sig sebesar 0.000. Hal tersebut membuktikan bahwa $\mathrm{H}_{\mathrm{o}}$ ditolak, yang bermakna variabel akuntabilitas berpengaruh terhadap kepercayaan donatur. Karena nilai sig lebih kecil dari 0.05 .

\section{Hasil Uji F (Simultan)}

Tabel 4.10

Hasil uji simultan

\begin{tabular}{|c|c|c|c|c|c|c|}
\hline \multicolumn{7}{|c|}{ ANOVA $^{\mathrm{b}}$} \\
\hline \multicolumn{2}{|c|}{ Model } & $\begin{array}{l}\text { Squm } \\
\text { of } \\
\text { Square }\end{array}$ & df & $\begin{array}{l}\text { Mean } \\
\text { Square }\end{array}$ & $\mathrm{F}$ & Sig \\
\hline \multirow{3}{*}{1} & $\begin{array}{l}\text { Regresio } \\
\mathrm{n}\end{array}$ & $\begin{array}{r}193.10 \\
7\end{array}$ & 2 & 96.553 & $\begin{array}{r}17.51 \\
2\end{array}$ & $.000^{\mathrm{a}}$ \\
\hline & Residual & $\begin{array}{r}176.43 \\
6\end{array}$ & 32 & 5.514 & & \\
\hline & Total & $\begin{array}{r}369.54 \\
3\end{array}$ & 34 & & & \\
\hline \multicolumn{7}{|c|}{ a. Predictors : (Constant), Akuntabilitas, Transparansi } \\
\hline \multicolumn{7}{|c|}{ b. Dependent Variable : Kepercayaan } \\
\hline \multicolumn{7}{|c|}{ Sumber: Data diolah spss 16} \\
\hline
\end{tabular}

Hasil uji F, pengaruh transparansi dan akuntabilitas laporan keuangan terhadap kepercayaan donatur, diperoleh nilai $\mathrm{F}$ sebesar 17.512 dengan nilai sig sebesar 0.000 , karena tingkat signifikansi lebih kecil dari 0.05 maka $\mathrm{H}_{\mathrm{o}}$ ditolak, artinya variabel transparansi dan akuntabilitas secara simultan berpengaruh terhadap kepercayaan donatur.

\section{KESIMPULAN DAN SARAN}

\section{Kesimpulan}

Berdasarkan analisis data serta pembahasan yang dilakukan peneliti mengenai transparansi dan akuntbilitas laporan keuangan terhadap kepercayaan donatur di Yayasan Sosial Keagamaan Cangkir Yadufa, maka kesimpulan yang dapat diambil yakni :

1. Transparansi laporan keuangan tidak berpengaruh terhadap kepercayaan donatur di Yayasan Sosial Keagamaan Cangkir Yadufa.

2. Akuntabilitas laporan keuangan berpengaruh terhadap kepercayaan donatur di Yayasan Sosial Keagamaan Cangkir Yadufa. 
3. Transparansi dan akuntabilitas laporan keuangan secara simultan berpengaruh terhadap kepercayaan donatur di Yayasan Sosial Keagamaan Cangkir Yadufa.

4. Secara parsial terdapat nilai hubungan antara transparansi dan akuntabilitas laporan keuangan terhadap kepercayaan donatur.

5. Secara simultan terdapat nilai hubungan yang tinggi/kuat antara transparansi dan akuntabilitas laporan keuangan terhadap kepercayaan donatur secara simultan.

6. Transparansi dan akuntabilitas laporan keuangan dapat dipergunakan sebagai prediksi mengenai tingkat kepercayaan donatur di Yayasan Sosial Keagamaan Cangkir Yadufa pada waktu mendatang.

\section{Saran}

Berdasarkan dari kesimpulan penelitian ini, terdapat beberapa saran yang dapat dijabarkan yaitu sebagai berikut :

1. Bagi pihak internal Yayasan Sosial Keagamaan Cangkir Yadufa, agar pihak internal Yayasan Sosial Keagamaan Cangkir Yadufa lebih meningkat lagi transparansi dan akuntabilitas laporan keuangannya, sehingga dapat meningkatkan kepercayaan donatur untuk menyisihkan sebagaian sumber dayanya untuk di sumbangkan kepada Yayasan Sosial Keagamaan Cangkir Yadufa.

2. Bagi peneliti selanjunya agar bisa memperbanyak variabel baru yang bisa meningkatkan atau mempengaruhi tingkat transparansi dan akuntabilitas laporan keuangan terhadap kepercayaan donatur. Sehingga diperoleh hasil penelitian yang lebih baik lagi.

\section{DAFTAR PUSTAKA}

Anggi Melisah Putri, (2014). "Pengaruh Transparansi penyaluran dana Pendidikan di Yayasan Dana Sosial Al-Falah Cabang Sidoarjo Terhadap Kepercayaan Donatur.

Athifah, Nur Bayinah Ai, Syamsul Bahri Efri. (2018). "Pengaruh Akuntabilitas Publik dan Transparansi Laporan Keuangan Terhadap Kepercayaan Donatur pada Yayasan PPPA Daarul Qur'an Nusantara". Perisai, Vol 2 (1)

Aulina Putri, M. Rizal Yahya, (2016). "Pengaruh Akuntabilitas Terhadap Kinerja Baitul Mal Kota Banda Aceh". Jurnal Ilmiah Mahasiswa Ekonomi Akuntansi Vol.1 No.1 Hal 357-367 Dokumen Yayasan Sosial Keagamaan Cangkir Yadufa, majalah Yayasan Sosial Keagamaan Cangkir Yadufa.

Dwi Priyatno, "Mandiri Belajar SPSS.” (Jakarta:Buku Kita, 2008).

Muh. Ashari Assagaf, (2016). "Pengaruh Akuntabilitas dan Transparansi Pengelolaan Zakat Terhadap minat Muzakki Membayar Zakat”. UIN Alauddin Makassar.

Nur Hayati DKK, (2013). "Pengaruh shariah compliance, transparansi, akuntabilitas dan kompetensi sumber daya manusia terhadap pengelola dana zakat pada organisasi pengelola zakat di kabupaten sidoarjo".

Sedarmayanti, \& Hidayat, S. (2011). Metodologi Penelitian. Bandung: Mandar Maju

Sugiyono, 2011, Metode Penelitian Kuantitatif, Kualitatif, dan R\&D. $\quad$ Bandung: $\quad$ Alfabeta, Hlm. 240 Sumber data: Profil Yayasan Sosial Keagamaan Cangkir Yadufa. 